\title{
Características estruturais e acúmulo de forragem em capim-tanzânia sob pastejo rotativo
}

\author{
Anderson de Moura Zanine ${ }^{1^{*}}$, Domicio do Nascimento Júnior ${ }^{2}$, Manoel Eduardo Rozalino \\ Santos $^{1}$, Karine da Silva Pena ${ }^{1}$, Sila Carneiro da Silva ${ }^{3}$, André Fischer Sbrissia ${ }^{4}$
}

\author{
1 Programa de Pós-Graduação em Zootecnia - Universidade Federal de Viçosa. \\ 2 Departamento de Zootecnia - Universidade Federal de Viçosa. \\ ${ }^{3}$ Departamento de Zootecnia-USP/ESALQ. \\ 4 Universidade do Estado de Santa Catarina.
}

RESUMO - Esta pesquisa foi conduzida com o objetivo de avaliar as características estruturais e o acúmulo de forragem do capim-tanzânia (Panicum maximum cv. Tanzânia) sob pastejo rotativo e submetido às combinações de duas frequências de pastejo (tempo para o dossel atingir 90 ou 95\% de interceptação da luz - IL) e duas alturas pós-pastejo (30 ou 50 cm). Adotou-se um arranjo fatorial $2 \times 2$ em delineamento de blocos completos casualizados com três repetições. As alturas pré-pastejo foram estáveis durante o período experimental (7/11/2005 a 12/10/2006) e corresponderam a 65 e $75 \mathrm{~cm}$ para metas de 90 e $95 \%$ de IL, respectivamente. Os pastos manejados com altura pós-pastejo de $50 \mathrm{~cm}$ e com $90 \%$ de IL apresentaram maior número de ciclos de pastejo em comparação àqueles submetidos à altura pós-pastejo de $30 \mathrm{~cm}$ e com 95\% de IL. Padrão de resposta contrário ocorreu para o intervalo de pastejo. O acúmulo de lâmina foliar (LF) foi maior no verão, intermediário no final da primavera e menor no outono e no inverno e início da primavera. O acúmulo de FT e de LF foi maior nos pastos manejados com $30 \mathrm{~cm}$ de altura pós-pastejo em comparação àqueles com $50 \mathrm{~cm}$. Por outro lado, os efeitos da condição pré-pastejo no acúmulo de FT dependeu do resíduo usado. Os níveis de IL (90 ou 95\%) não influenciaram o acúmulo de lâminas foliares. As combinações de intensidades e frequências de pastejo resultaram em pouca variação na composição morfológica da forragem, exceto no outono, quando se observou maior percentual de material morto em pastos manejados com $50 \mathrm{~cm}$ de altura póspastejo em comparação àqueles sob $30 \mathrm{~cm}$ de resíduo. O pastejo rotativo do capim-tanzânia deve ser iniciado com 95\% de IL pelo dossel e encerrado com $30 \mathrm{~cm}$ de altura pós-pastejo. Quando necessário, e para gerar flexibilidade no manejo do pastejo, o capim-tanzânia pode ser pastejado com 90\% de IL pelo dossel.

Palavras-chave: acúmulo de forragem, altura do pasto, interceptação de luz, manejo do pastejo

\section{Structural characteristics and herbage accumulation of Tanzania guineagrass subjected to rotational stocking}

\begin{abstract}
The aim of this study was to evaluate the structural characteristics and herbage accumulation of tanzania guineagrass (Panicum maximum cv. Tanzania) under rotational grazing and subjected to combinations of two grazing frequencies (time for the canopy to intercept 90 or $95 \%$ of the incident light) and two post-grazing heights (30 or $50 \mathrm{~cm}$ ). Treatments were assigned to experimental units according to a $2 \times 2$ factorial arrangement in a completely randomized design, with three replications. Sward heights at pre-grazing were consistent during the experimental period and were of around 65 and $75 \mathrm{~cm}$, for $90 \%$ and $95 \%$ of light interception (LI), respectively. Pastures managed with post-grazing height of $50 \mathrm{~cm}$ and $90 \%$ of LI had higher number of grazing cycles when compared with those submitted to post-grazing height of $30 \mathrm{~cm}$ and 95\% of LI. Herbage mass production was higher in summer, intermediate in late spring and lowest in fall and winter and early spring. Herbage mass and lamina leaves production were higher in pastures managed with post-grazing height of $30 \mathrm{~cm}$ when compared with post-grazing height of $50 \mathrm{~cm}$. Nevertheless, the effects of frequency on herbage mass production were associated with the post-grazing height used. The LI levels (90 or 95\%) did not affect leaf lamina production. The combinations of frequency and severity of grazing resulted in little variation in the morphological composition of forage, except in the autumn, when there was a higher percentage of dead material in pastures managed with post-grazing height of $50 \mathrm{~cm}$ when compared with those with post-grazing height of $30 \mathrm{~cm}$. The rotational grazing of tanzania guineagrass should be initiated when canopy intercepts $95 \%$ of incident light until a post-grazing height of $30 \mathrm{~cm}$. When necessary and in order to generate flexibility in grazing management, the tanzania guineagrass can be grazed with $90 \%$ of light interception.
\end{abstract}

Key Words: forage production, grazing management, light interception, sward height

Recebido em 10/2/2010 e aprovado em 15/12/2010

Correspondências devem ser enviadas para: andersonzanine@ufmt.br

*Endereço atual: Universidade Federal de Mato Grosso - Campus de Rondonópolis. 


\section{Introdução}

A pecuária brasileira ainda é caracterizada, em geral, pelos baixos índices de produtividade, o que é consequência, entre outros fatores, do manejo inadequado das pastagens. Isso se deve, em parte, ao desconhecimento da ecofisiologia das plantas forrageiras tropicais e de seus limites de tolerância ao pastejo sob distintos ambientes (Da Silva, 2004).

No âmbito do manejo do pastejo, o emprego inadequado da frequência e da intensidade de desfolhação pode resultar em menor produtividade do pasto, bem como na formação de uma estrutura de pasto inadequada, caracterizada por maiores acúmulos de colmo e de tecidos mortos (Bueno, 2003; Barbosa et al., 2007).

Em pastos de gramíneas tropicais manejados sob lotação intermitente, a frequência de pastejo correspondente ao tempo para o dossel interceptar 95\% da luz tem otimizado o acúmulo de forragem e as características estruturais do pasto (Carnevalli et al., 2006; Barbosa et al., 2007; Pedreira et al., 2007; Giacomini et al., 2009), com efeitos positivos sobre a produção animal (Difante et al., 2009). Por outro lado, o emprego da intensidade de pastejo, caracterizada pela altura do resíduo pós-pastejo, pode ser mais flexível, de acordo com o objetivo do pecuarista, se obter maior desempenho animal ou maior produção por área (Difante et al., 2009).

A interrupção do período de descanso quando o dossel intercepta $95 \%$ da luz pode ser muito estrita, especialmente em ambientes favoráveis ao crescimento do pasto, como em pastagens adubadas e, ou, irrigadas. Nesses casos, é comum que, concomitantemente, um número maior de pastos alcance a condição ideal de pastejo relativamente ao número necessário. Nessa situação, para gerar flexibilidade de manejo, entre as ações que podem ser adotadas, destaca-se a realização do pastejo em tempo mais precoce em relação à meta ideal de $95 \%$ de interceptação de luz pelo dossel.

A interrupção da rebrotação dos pastos antes de $95 \%$ de interceptação de luz pode resultar em melhor valor nutritivo da forragem e, por conseguinte, melhorar o desempenho animal em determinado período de tempo. Entretanto, o uso contínuo desse manejo pode comprometer a reconstituição dos compostos de reserva da planta forrageira e reduzir sua persistência (Sbrissia et al., 2009).

Objetivou-se avaliar a produção e as características estruturais do capim-tanzânia em pastejo rotativo submetido às combinações de frequências e intensidades de pastejo.

\section{Material e Métodos}

O experimento foi realizado em área do Departamento de Zootecnia da Universidade Federal de Viçosa (UFV), em Viçosa, Minas Gerais (lat. $20^{\circ} 45^{\prime}$ S, long. $42^{\circ} 51^{\prime} \mathrm{W}$ e alt. $651 \mathrm{~m}$ ). O clima de Viçosa, segundo a classificação de Köppen, é do tipo Cwa, subtropical, com inverno ameno e seco, e estações seca e chuvosa bem definidas. A temperatura média anual dos últimos 10 anos foi de $19^{\circ} \mathrm{C}$, oscilando entre $22^{\circ} \mathrm{C}$ e $15{ }^{\circ} \mathrm{C}$ para as médias de máxima e mínima. A umidade relativa do ar é de aproximadamente $80 \%$ e a precipitação média nos últimos 10 anos foi $1.340 \mathrm{~mm}$. As informações das condições climáticas durante o período experimental foram fornecidas pela estação meteorológica da UFV, cujos dados foram usados para cálculo do balanço hídrico mensal, considerando-se uma capacidade de

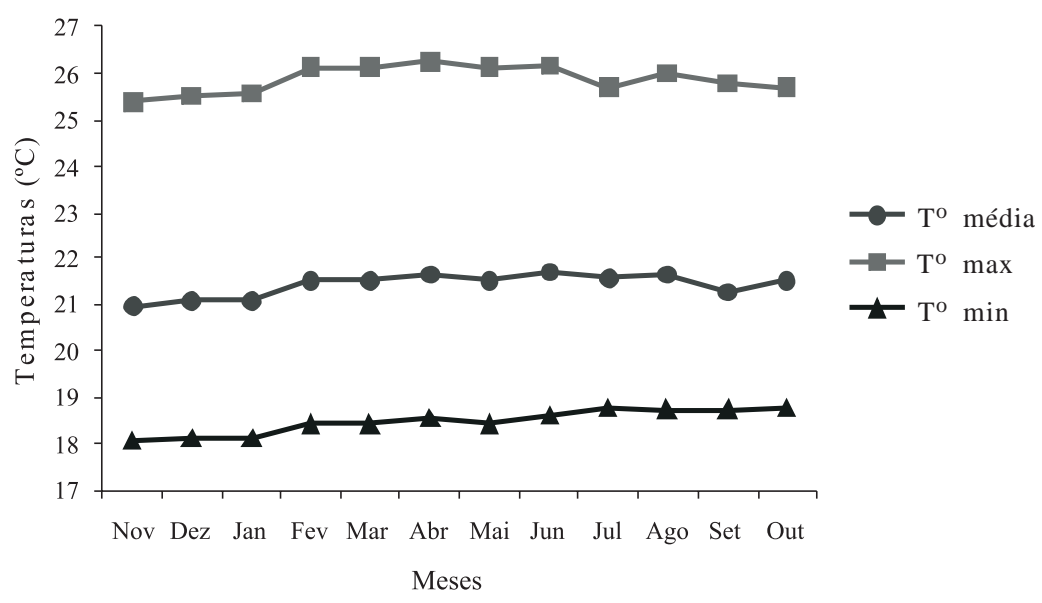

Figura 1 - Temperaturas média, máxima e mínima mensal ao longo do período experimental (novembro de 2005 a outubro de 2006 ), em Viçosa, Minas Gerais. 
armazenamento de água de $50 \mathrm{~mm}$ (Thornthwaite \& Mather, 1955) (Figuras 1 e 2).

A espécie forrageira estudada foi o Panicum maximum Jacq. cv. Tanzânia, cujo estabelecimento foi feito em 7/1/2005, por meio de semeadura, utilizando-se $3 \mathrm{~kg}$ de sementes puras viáveis por hectare. No dia 25 de março de 2005, a área foi submetida a um pastejo leniente com a finalidade de estimular o perfilhamento das plantas e, logo em seguida, à adubação com 60 kg/ha de nitrogênio na forma de ureia. A partir dessa data, foi feito controle manual de plantas invasoras e a área foi manejada com desfolhação intermitente usando-se bovinos mestiços até o início da primavera. Na primeira quinzena de outubro de 2005, foi realizado o rebaixamento do pasto para $35 \mathrm{~cm}$, utilizando-se roçadeira costal. As avaliações iniciaram no dia 7/11/2005 e encerraram no dia 12/10/2006. A área total utilizada no experimento foi de $2.184 \mathrm{~m}^{2}$, subdividida em 12 piquetes de $144 \mathrm{~m}^{2}$ cada (unidades experimentais) por meio de cerca eletrificada. Os tratamentos corresponderam a combinações entre dois intervalos (período de tempo necessário para o dossel atingir 90 e 95\% de interceptação da luz incidente durante a rebrotação - IL) e duas intensidades de pastejo (30 e $50 \mathrm{~cm}$ de altura pós-pastejo) e foram alocados às unidades experimentais segundo um arranjo fatorial $2 \times 2 \mathrm{e}$ delineamento de blocos completos casualizados com três repetições. Os tratamentos foram denominados 90/30, 90/50, 95/30 e 95/50 (IL/altura pós-pastejo).

O solo da área experimental é classificado como Argissolo vermelho-amarelo, com textura franco-argilosa (EMBRAPA, 1999). Foram coletadas amostras de solo a na profundidade de $0-20 \mathrm{~cm}$ para análise das características químicas no laboratório do Departamento de Solos da UFV.

Não houve necessidade de fazer a correção ou a adubação na área para a semeadura da gramínea, tendo em vista a elevada fertilidade natural do solo, bem como seu alto valor de pH e ausência de alumínio trocável (Tabela 1).

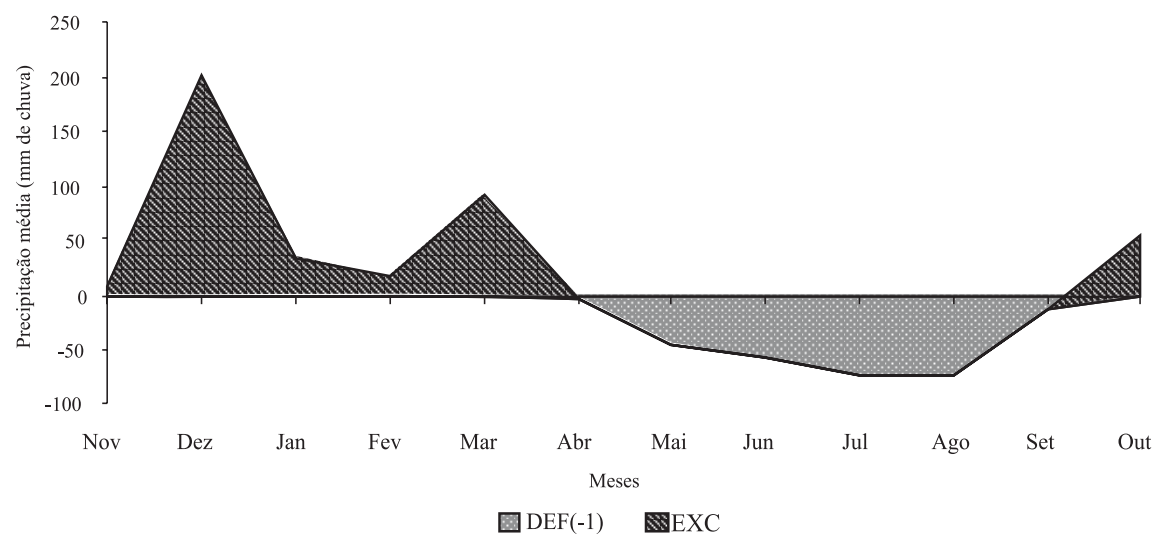

Figura 2 - Balanço hídrico mensal durante o período experimental (novembro de 2005 a outubro de 2006).

Tabela 1 - Características químicas de amostras de solo da camada de 0-20 cm da área experimental

\begin{tabular}{|c|c|c|c|c|c|c|c|c|c|c|c|}
\hline \multirow[t]{2}{*}{ Trat. } & \multirow[t]{2}{*}{ Piq* } & $\mathrm{pH}$ & $\mathrm{P}$ & K & $\mathrm{Ca}^{2+}$ & $\mathrm{Mg}^{2+}$ & $\mathrm{Al}^{3+}$ & $\mathrm{H}+\mathrm{Al}$ & CTC & \multirow{2}{*}{$\begin{array}{l}\mathrm{V} \\
\%\end{array}$} & \multirow{2}{*}{$\frac{\mathrm{MO}}{\mathrm{dag} / \mathrm{kg}}$} \\
\hline & & $\mathrm{H}_{2} \mathrm{O}$ & \multicolumn{2}{|c|}{$\mathrm{mg} / \mathrm{dm}^{3}$} & \multicolumn{5}{|c|}{$\mathrm{cmol}_{\mathrm{c}} / \mathrm{dm}^{3}$} & & \\
\hline \multicolumn{12}{|c|}{ Bloco I } \\
\hline $95 / 50$ & 2 & 6,7 & 26,2 & 315 & 6,4 & 0,9 & 0 & 1,5 & 10,1 & 84 & 3,4 \\
\hline $90 / 30$ & 3 & 6,4 & 27,3 & 325 & 6,9 & 0,9 & 0 & 1,4 & 9,9 & 82 & 3,7 \\
\hline $90 / 50$ & 4 & 6,9 & 27,9 & 343 & 6,5 & 1,0 & 0 & 1,5 & 10,2 & 80 & 3,5 \\
\hline $95 / 50$ & 6 & 6,4 & 24,5 & 286 & 6,2 & 0,9 & 0 & 1,5 & 9,6 & 78 & 3,2 \\
\hline $90 / 30$ & 7 & 6,4 & 22,9 & 334 & 5,8 & 1,0 & 0 & 1,3 & 9,7 & 80 & 3,3 \\
\hline $90 / 50$ & 8 & 6,8 & 27,5 & 302 & 6,7 & 1,1 & 0 & 1,2 & 10,1 & 83 & 3,7 \\
\hline \multicolumn{12}{|c|}{ Bloco III } \\
\hline $95 / 30$ & 9 & 7,1 & 27,3 & 289 & 6,5 & 1,1 & 0 & 2,4 & 10,2 & 70 & 3,4 \\
\hline
\end{tabular}

*Piquete. CTC: capacidade de troca de cátions; V: saturação de bases; MO: matéria orgânica. 
Durante o experimento, foram utilizados $150 \mathrm{~kg} / \mathrm{ha}$ de nitrogênio, na forma de ureia, divididos em três doses de $50 \mathrm{~kg} / \mathrm{ha}$, após a saída dos animais dos piquetes. Como o intervalo de pastejo e as condições de entrada dos animais nos piquetes foram variáveis, as datas de aplicação também foram distintas, porém estabelecidas de forma que todos os tratamentos recebessem a mesma quantidade de nitrogênio ao final do período experimental.

Os pastejos foram realizados de forma intermitente utilizando-se grupo de animais (mob grazing) (Mckenzie et al., 1999) para desfolhações rápidas. O número de animais usados em cada ciclo de pastejo foi calculado para que o tempo de rebaixamento dos pastos não excedesse um período diurno. Para isso, foram utilizados bovinos mestiços e de peso corporal médio de $460 \mathrm{~kg}$. Ao serem removidos dos piquetes, os bovinos eram colocados em um pastoreserva e só retornavam à unidade experimental quando algum piquete atingia novamente as metas pré-pastejo estabelecidas (90 ou 95\% de IL). Os piquetes foram pastejados por um número variável de animais, dependendo da meta de altura pós-pastejo almejada.

O monitoramento da interceptação luminosa pelo dossel foi realizado no momento da saída dos animais dos piquetes (condição pós-pastejo de 30 ou 50 cm) e durante a rebrotação, até que as metas pré-pastejo de 90 e 95\% de IL fossem atingidas. Para as avaliações, foi utilizado um equipamento analisador de dossel - AcCUPAR Linear PAR/LAI ceptometer, Model PAR-80 (DECAGON Devices). Foram realizadas leituras em 16 pontos de amostragem por piquete, tomando-se em cada ponto uma leitura acima e outra abaixo do dossel, utilizando-se a superfície do solo como referência.

A altura do pasto foi medida utilizando-se uma régua e as leituras realizadas no plano das folhas superiores em torno da régua em 16 pontos aleatórios por unidade experimental nas condições de pré-pastejo e pós-pastejo.

A determinação da massa de forragem nas condições de pré e de pós-pastejo foi realizada por meio de amostragens diretas. No último dia do período de descanso (condição de pré-pastejo) e após o período de ocupação (condição póspastejo), duas amostras representativas dos pastos foram colhidas por piquete. Para isso, foi utilizada uma armação metálica de aproximadamente $0,50 \mathrm{~m}^{2}(0,70 \times 0,70 \mathrm{~m})$ para colheita, no nível da superfície do solo, de todos os perfilhos contidos em seu interior.

De maneira separada, em cada ciclo de pastejo, o acúmulo de forragem também foi quantificado pela colheita de plantas de capim-tanzânia presentes no interior da armação metálica de $0,50 \mathrm{~m}^{2}$ na condição pré-pastejo. Durante todo o período experimental, foram escolhidos seis pontos representativos da altura média dos pastos e a forragem acima dos resíduos de 30 ou $50 \mathrm{~cm}$ foi colhida. Em cada amostra, os componentes morfológicos (lâmina foliar, colmo mais bainha foliar e material morto) foram separados manualmente e, depois, colocados em estufa de ventilação forçada para secagem até peso constante.

Os dados relativos às variáveis descritivas da condição do pasto, como alturas pré e pós-pastejo e intervalo de pastejo foram analisados por meio de estatística descritiva. As demais variáveis foram agrupadas por época do ano, devido à natureza variável dos intervalos de pastejo ocorridos para os tratamentos avaliados. Para isso, foram calculadas médias ponderadas levando-se em consideração o número e a duração dos ciclos de pastejo para cada repetição, e os resultados agrupados nas seguintes épocas do ano: final de primavera (novembro e dezembro de 2005); verão (janeiro a março de 2006); outono (abril a junho de 2006); e inverno/ início da primavera (julho a outubro de 2006).

Os dados assim agrupados foram submetidos à análise de variância utilizando-se o procedimento GLM do pacote estatístico SAS (SAS Institute, 1993). A comparação de médias, quando necessária, foi realizada por meio do teste de Tukey adotando-se nível de significância de 10\%.

\section{Resultados e Discussão}

O intervalo médio de pastejos (IMP) foi influenciado $(\mathrm{P}<0,10)$ pela interceptação de luz (IL) no pré-pastejo, pela altura pós-pastejo e pelas épocas do ano (Figura 3). Em média, os pastos manejados com 90 e $95 \%$ de IL apresentaram IMP de 52 e 64 dias, respectivamente. Pastos com $30 \mathrm{~cm}$ de resíduo apresentaram $(\mathrm{P}<0,10)$, em média, IMP superior (62 dias) quando comparados àqueles com $50 \mathrm{~cm}$ de resíduo (55 dias). Verificou-se também que o IMP foi crescente a partir do final da primavera (31 dias) e do verão (31 dias) até o outono (64 dias) e o inverno e início da primavera (106 dias).

Na condição pós-pastejo, a interceptação de luz pelo dossel manejado com $30 \mathrm{~cm}$ de resíduo foi de 40\%, enquanto, no pasto manejado com $50 \mathrm{~cm}$, foi de $67 \%$. Essa diferença nos valores de interceptação de luz favoreceu a rebrotação dos pastos submetidos ao pastejo mais leniente (50 cm), o que resultou em menor intervalo médio de pastejo e maior número de ciclos de pastejo no período experimental. Esse resultado corrobora aqueles obtidos por Barbosa et al. (2007) com o capim-tanzânia e por Lopes (2006) com o capim-mombaça. Na condição pré-pastejo, pastos manejados com $90 \%$ de IL alcançaram menor estádio de desenvolvimento em comparação àqueles submetidos 

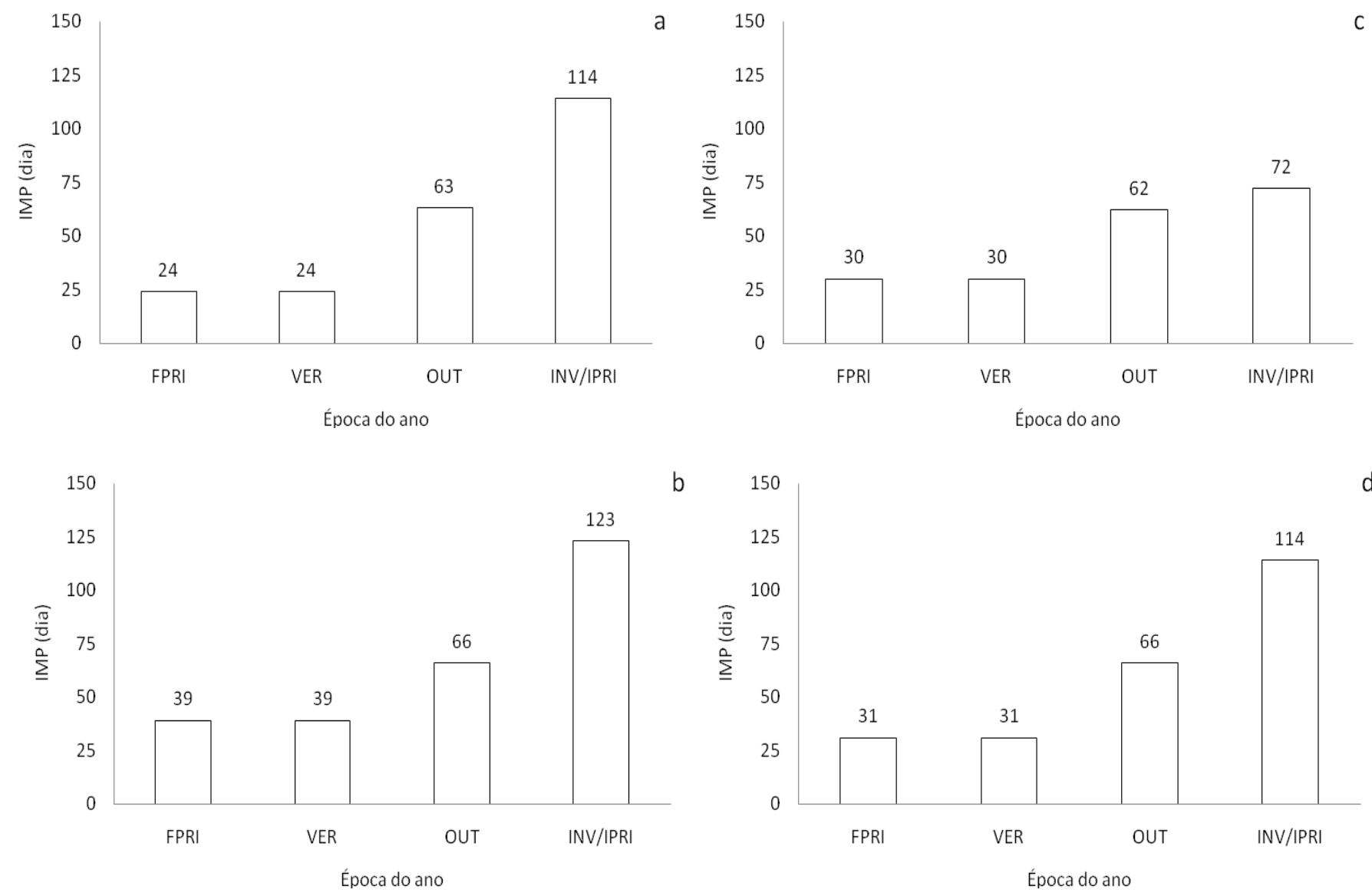

FPRI = final da primavera; VER = verão; OUT = outono; INV/IPRI = inverno/início da primavera.

Figura 3 - Intervalo médio de pastejo (IMP) nos tratamentos de $30 \mathrm{~cm}$ de altura pós-pastejo e interceptação luminosa de 90 (a) e $95 \%$ (b) e 50 cm de altura pós-pastejo e 90 (c) e 95\% (d) durante as épocas do ano.

à condição de 95\% de IL. Isso justifica o menor intervalo de pastejo (Figura 3) e, por conseguinte, o maior número de ciclo de pastejo ocorrido em pastos manejados com $90 \%$ de IL.

O intervalo médio de pastejo oscilou entre épocas do ano (Figura 3), em razão das condições climáticas específicas verificadas nestas épocas (Figura 1). Nesse sentido, as condições climáticas favoráveis durante o final da primavera e o verão (Figuras 1 e 2) justificam o menor intervalo de pastejo ocorrido nesta época e o maior intervalo de pastejo verificado no inverno e início da primavera (Figura 3). Esses resultados indicam a necessidade de empregar períodos de descansos variáveis quando as estratégias de manejo do pastejo são baseadas no controle rigoroso da condição do pasto em pré-pastejo. Além disso, a adoção desse manejo garante melhor qualidade e menor variabilidade nas características da forragem produzida, contrariamente ao constatado quando se adotam períodos fixos de descanso (Pedreira et al., 2007).

A manutenção das alturas de resíduo pós-pastejo (30 ou $50 \mathrm{~cm}$ ) foram alcançadas satisfatoriamente, independentemente do nível de interceptação luminosa usado. Mesmo durante o outono, época em que os pastos possuíam maior número de perfilhos em estádio reprodutivo (Zanine, 2007), foi possível manter os resíduos pós-pastejo nas metas almejadas. Infere-se, portanto, que o emprego desses critérios de manejo pré-pastejo (90 ou $95 \%$ de IL) dispensa a realização de roçadas no pasto de capim-tanzânia para manutenção do resíduo pós-pastejo almejado, consistindo em vantagem para o sistema de produção pastoril.

A altura do pasto em pré-pastejo foi homogênea para as metas de 90 ou 95\% de IL. As maiores alturas de pré-pastejo no manejo a $95 \%$ de IL $(75 \mathrm{~cm})$ foram resultados de intervalos de pastejos mais longos (Figura 3). Contrariamente, as menores alturas de pré-pastejo nos pastos sob 90\% de IL (65 cm) foram consequência de seu menor intervalo de pastejo (Figura 3). Esses resultados são similares àqueles verificados por Barbosa et al. (2007), que obtiveram valores de altura pré-pastejo em torno de 60 e $70 \mathrm{~cm}$ para o capimtanzânia manejado com 90 ou 95\% de IL, respectivamente.

Conforme observado por outros autores (Carnevalli et al., 2006; Mello \& Pedreira, 2004; Barbosa et al., 2007; 
Pedreira et al., 2007), existe correspondência entre interceptação luminosa durante a rebrotação e altura do pasto. Essa correspondência é relativamente estável e, por isso, o nível de interceptação de luz pelo dossel pré-pastejo pode ser estimado pela altura do pasto. Nesse contexto, como a interceptação de luz é de difícil avaliação e monitoramento, a altura do pasto consiste em parâmetro adequado e consistente, de baixo custo e de facilidade operacional, que pode ser recomendada em condições práticas para nortear o manejo do pastejo do capim-tanzânia.

Exceto na época de inverno e início da primavera, a massa de forragem pré-pastejo foi maior $(\mathrm{P}<0,10)$ nos pastos sob 95\% de IL (6072 kg/ha de MS, em média) em comparação àqueles com $90 \%$ de IL (5585 kg/ha de MS, em média) (Tabela 2). Isso foi consequência do maior intervalo de pastejo nos pastos com 95\% de IL (Figura 3), o que resultou no seu maior crescimento por ciclo de pastejo. Contudo, durante o inverno e o início da primavera, as condições climáticas restritivas ao pasto (Figuras 1 e 2) resultaram em longo período de descanso do capim-tanzânia (Figura 3), o que pode ter minimizado as diferenças de massa de forragem pré-pastejo entre os pastos sob 90 e 95\% de IL.

Os pastos rebaixados até $30 \mathrm{~cm}$ apresentaram $(\mathrm{P}<0,10)$ maior massa de forragem pré-pastejo durante o final da primavera, no verão e no outono; porém, durante o inverno e o início da primavera, aqueles manejados com $50 \mathrm{~cm}$ de

Tabela 2 - Massa de forragem (kg/ha de MS) pré-pastejo do capim-tanzânia sob pastejo com 90 e 95\% de IL e alturas pós-pastejo (APP) de 30 e $50 \mathrm{~cm}$ durante as épocas do ano

\begin{tabular}{|c|c|c|c|}
\hline \multirow{2}{*}{$\overline{\mathrm{APP}}(\mathrm{cm})$} & \multicolumn{3}{|c|}{ Interceptação luminosa (\%) } \\
\hline & 90 & 95 & Média \\
\hline & \multicolumn{3}{|c|}{ Final da primavera } \\
\hline 30 & 7480aB(346) & $8120 \mathrm{aA}(277)$ & 7800a(74) \\
\hline 50 & 5330bB(218) & 6420bA(166) & $5870 \mathrm{~b}(103)$ \\
\hline \multirow[t]{2}{*}{ Média } & $6400 \mathrm{~B}(201)$ & 7270A(158) & 6830A'(188) \\
\hline & \multicolumn{3}{|c|}{ Verão } \\
\hline 30 & $6460 \mathrm{aB}(184)$ & 7450aA(233) & $7000 a(100)$ \\
\hline 50 & $6620 \mathrm{aB}(141)$ & 6910bA(281) & $6760 \mathrm{~b}(43)$ \\
\hline \multirow[t]{2}{*}{ Média } & $6540 \mathrm{~B}(28)$ & $7180 \mathrm{~A}(68)$ & $6880 A^{\prime}(75)$ \\
\hline & \multicolumn{3}{|c|}{ Outono } \\
\hline 30 & 5910aB(102) & 6550aA(104) & 6230a(80) \\
\hline 50 & 4740bB(46) & 5580bA(205) & 5160b(70) \\
\hline \multirow[t]{2}{*}{ Média } & $5330 \mathrm{~B}(116)$ & $6070 \mathrm{~A}(98)$ & 5690B'(103) \\
\hline & \multicolumn{3}{|c|}{ Inverno/Início da primavera } \\
\hline 30 & 3190bA(27) & 3370bA(109) & $3280 b(22)$ \\
\hline 50 & 4950aA(91) & $4170 \mathrm{aB}(111)$ & $4560 a(55)$ \\
\hline Média & $4070 \mathrm{~A}(62)$ & $3770 \mathrm{~A}(75)$ & $3920 C^{\prime}(48)$ \\
\hline
\end{tabular}

Números entre parênteses correspondem ao erro-padrão da média.

Médias com mesma letra minúscula na coluna, dentro de época, não diferem $(\mathrm{P}>0,10)$ entre si.

Médias com mesma letra maiúscula na linha, dentro de época, não diferem $(\mathrm{P}>0,10)$ entre si.

Médias seguidas de letra maiúscula acrescida de (’) comparam épocas do ano. altura pós-pastejo acumularam maior $(\mathrm{P}<0,10)$ massa de forragem no pré-pastejo (Tabela 2). Desse modo, na maioria das épocas do ano, o pastejo mais intenso resultou em maior massa de forragem pré-pastejo em comparação ao pastejo mais leniente, o que foi consequência do maior perfilhamento em pastos manejados com resíduo mais baixo (Zanine, 2007). Realmente, sob desfolhação severa, há redução do tamanho de perfilhos, acompanhada pelo aumento do número de perfilhos (Matthew et al., 1999; Sbrissia \& Da Silva, 2008; Sbrissia et al., 2010).

Os valores de massa de forragem pré-pastejo foram maiores no final da primavera e no verão, intermediários no outono, e inferiores no inverno e no início da primavera (Tabela 2). Em épocas de clima favorável ao maior crescimento do pasto (final da primavera e verão), a massa de forragem pré-pastejo foi maior, devido ao maior perfilhamento do capim-tanzânia nesse período. Por outro lado, o menor perfilhamento no outono e, sobretudo, no inverno e início de primavera contribuiu para a redução da massa de forragem pré-pastejo nestas épocas (Zanine, 2007).

Para cada condição de pré-pastejo, o período de descanso terminou quando os pastos estavam com alturas similares, independente da época do ano. Mesmo assim, a massa de forragem pré-pastejo foi distinta entre as épocas (Tabela 2), indicando que a densidade volumétrica da forragem foi variável com o tempo.

Os valores de massa de forragem pós-pastejo foram maiores $(\mathrm{P}<0,10)$ na condição pré-pastejo de $95 \%$ de IL durante o outono. Contudo, durante o inverno e início da primavera, esse mesmo padrão de resposta ocorreu apenas nos pastos manejados com $30 \mathrm{~cm}$ de altura ao término do pastejo (Tabela 3). A maior participação de colmo no resíduo pós-pastejo do capim-tanzânia sob 95\% de IL pode explicar esse resultado. O colmo tem maior teor de matéria seca, bem como maior densidade volumétrica (Moore et al., 1987), o que determina maior massa de forragem pós-pastejo quando esse componente morfológico tem elevada participação no resíduo.

Durante o outono, pastos rebaixados para $30 \mathrm{~cm}$ apresentaram $(\mathrm{P}<0,10)$ maior massa de forragem pós-pastejo em comparação àqueles com $50 \mathrm{~cm}$ de resíduo; entretanto, durante o inverno e início da primavera, um padrão de resposta contrário ocorreu (Tabela 3). Esses resultados caracterizam interação entre estação do ano e estratégia de manejo do pastejo e indicam a necessidade de estudos durante várias estações para melhor compreensão dos efeitos das estratégias de manejo do pastejo sobre as características do pasto.

Além disso, como as condições de clima são menos restritivas ao crescimento do pasto no outono que no 
inverno (Figura 1), é natural que os menores valores de massa de forragem pós-pastejo tenham ocorrido no inverno (Tabela 3).

De modo geral, a variabilidade das massas de forragem pré e pós-pastejo foram maiores nos pastos sob desfolhação mais intensa (30 cm de resíduo) que naqueles sob desfolhação mais leniente (50 cm de resíduo), o que indica maior instabilidade na estrutura do pasto na primeira condição de manejo. Por outro lado, com exceção da massa de forragem pós-pastejo, que variou mais em pastos manejados com $95 \%$ de IL que naqueles com $90 \%$ de IL, menor variabilidade das massas de forragem pré-pastejo ocorreu em função do nível de interceptação de luz a que os pastos foram submetidos. Esse padrão de resposta indica que os dois critérios de manejo pré-pastejo (90 e 95\% de IL) não divergem muito quanto à variabilidade dos valores de massa de forragem durante o ano.

O acúmulo de lâmina foliar do capim-tanzânia foi diferenciado nas épocas do ano (Tabela 4), com maiores valores $(\mathrm{P}<0,10)$ no verão, intermediários no final da primavera e inferiores no outono e no inverno e início de primavera. Tanto no final da primavera quanto no verão, os pastos manejados com 95\% de IL apresentaram $(\mathrm{P}<0,10)$ maior acúmulo de lâmina foliar em comparação àqueles com 90\% de IL. Nessas mesmas épocas, pastos mantidos com resíduo pós-pastejo de $30 \mathrm{~cm}$ expressaram $(\mathrm{P}<0,10)$ maior acúmulo de lâmina foliar em relação aos mantidos com $50 \mathrm{~cm}$ de resíduo. Os níveis de interceptação luminosa não influenciaram $(\mathrm{P}>0,10)$ o acúmulo de lâmina foliar durante $\mathrm{o}$ outono e o inverno e início de primavera. Nestas épocas, porém, as alturas de resíduo pós-pastejo apresentaram $(\mathrm{P}<0,10)$ padrões de resposta distintos, uma vez que, no outono, pastos submetidos a $30 \mathrm{~cm}$ de resíduo apresentaram

Tabela 3 - Médias da massa de forragem (kg MS/ha) pós-pastejo de capim-tanzânia sob lotação rotativa durante o outono e inverno/início da primavera

\begin{tabular}{|c|c|c|c|}
\hline \multirow[t]{2}{*}{ APP $(\mathrm{cm})$} & \multicolumn{3}{|c|}{ Interceptação luminosa (\%) } \\
\hline & 90 & 95 & Média \\
\hline & & Outono & \\
\hline 30 & $3010 \mathrm{aB}(182)$ & $3400 \mathrm{aA}(46)$ & $3200 a(54)$ \\
\hline 50 & 2380bB(79) & 3310bA(33) & 2850b(84) \\
\hline \multirow[t]{2}{*}{ Média } & $2690 \mathrm{~B}(75)$ & $3350 \mathrm{~A}(34)$ & $3020 A^{\prime}(74)$ \\
\hline & \multicolumn{3}{|c|}{ Inverno/Início da primavera } \\
\hline 30 & $1140 \mathrm{bB}(42)$ & 1240bA(106) & 1190b(15) \\
\hline 50 & 2060aA(33) & 1810aB(15) & 1930a(23) \\
\hline Média & $1600 \mathrm{~A}(84)$ & $1070 \mathrm{~B}(53)$ & 1560B'(67) \\
\hline
\end{tabular}

Números entre parênteses correspondem ao erro-padrão da média; médias com mesma letra minúscula na coluna, dentro de época, não diferem $(\mathrm{P}>0,10)$ entre si. Médias com mesma letra maiúscula na linha, dentro de época, não diferem $(\mathrm{P}>0,10)$ entre si.

Médias seguidas de letra maiúscula acrescida de (') comparam épocas do ano. maior acúmulo de lâmina foliar em relação aos manejados com 50 cm de resíduo; mas, no inverno e início de primavera, a resposta foi contrária (Tabela 4).

De modo geral, nas épocas de menor crescimento do capim-tanzânia (outono e inverno e início da primavera), o acúmulo de lâmina foliar não foi influenciado pela frequência de pastejo. Esse resultado permite deduzir que, em situações de menor crescimento do pasto, a realização do pastejo mais frequente (90\% de IL) não compromete a produção de forragem do pasto e pode constituir alternativa para flexibilizar o pastejo em épocas com clima limitante ao crescimento da planta.

O acúmulo de lâmina foliar foi maior nas épocas do ano em que o clima foi predisponente ao crescimento do capimtanzânia (verão e final da primavera), contrariamente ao ocorrido no outono e no inverno e início da primavera, épocas de clima restritivo ao crescimento do pasto (Tabela 4). De fato, nas épocas em que as taxas de acúmulo foram elevadas (verão e final da primavera), foram observadas altas taxas de alongamento e aparecimento de folhas, além de altas taxas de aparecimento de perfilhos (Zanine, 2007). Além disso, esses resultados confirmam a estacionalidade de produção do capim-tanzânia, ratificando os resultados encontrados por Pedreira et al. (2005) e Barbosa et al. (2007).

Durante o final da primavera e o verão, o maior acúmulo de lâmina foliar em pastos submetidos à frequência de desfolhação de 95\% de IL e altura pós-pastejo de 30 cm é resultado de condições adequadas para o crescimento do capim-tanzânia (Tabela 4). A interceptação de luz é premissa

Tabela 4 - Acúmulo de lâmina foliar (kg/ha de MS) do capimtanzânia sob lotação rotativa durante as épocas do ano

\begin{tabular}{|c|c|c|c|}
\hline \multirow[t]{2}{*}{ APP $(\mathrm{cm})$} & \multicolumn{3}{|c|}{ Interceptação luminosa (\%) } \\
\hline & 90 & 95 & Média \\
\hline & \multicolumn{3}{|c|}{ Final da primavera } \\
\hline 30 & 4360aB(168) & 4560aA(292) & $4460 \mathrm{a}(39)$ \\
\hline 50 & 3030bB(209) & 3220bA(189) & 3120b(34) \\
\hline Média & 3690B(125) & 3890A(127) & 3790B'(121) \\
\hline & \multicolumn{3}{|c|}{ Verão } \\
\hline 30 & $4380 \mathrm{aB}(393)$ & $4810 \mathrm{aA}(421)$ & $4590 \mathrm{a}(72)$ \\
\hline 50 & 4210bB(330) & 4770bA(281) & $4490 \mathrm{~b}(63)$ \\
\hline Média & 4290B(56) & $4790 \mathrm{~A}(44)$ & $4540 A^{\prime}(65)$ \\
\hline & \multicolumn{3}{|c|}{ Outono } \\
\hline 30 & 2090 a A(32) & $1800 \mathrm{aA}(38)$ & $1950 \mathrm{a}(25)$ \\
\hline 50 & 1650bA(110) & 1720bA(20) & 1690b(25) \\
\hline Média & $1870 \mathrm{~A}(42)$ & $1760 \mathrm{~A}(23)$ & $1820 C^{\prime}(33)$ \\
\hline & \multicolumn{3}{|c|}{ Inverno/Início da primavera } \\
\hline 30 & $1650 \mathrm{bA}(239)$ & 1610bA(191) & 1630b(32) \\
\hline 50 & 2380aA(66) & 1960aA(136) & $2170 \mathrm{a}(42)$ \\
\hline Média & $2020 \mathrm{~A}(72)$ & $1790 \mathrm{~A}(40)$ & $1900 C^{\prime}(59)$ \\
\hline
\end{tabular}

Médias com mesma letra minúscula na coluna, dentro de época, não diferem entre si $(\mathrm{P}>0,10)$.

Médias com mesma letra maiúscula na linha, dentro de época, não diferem entre si $(\mathrm{P}>0,10)$.

Médias seguidas de letra maiúscula acrescida de (') comparam épocas do ano. 
básica para ocorrência de fotossíntese e, por conseguinte, da produção de forragem no pasto. Esta é a razão pela qual os pastos com maior interceptação de luz (95\%) tiveram maior acúmulo de forragem (Tabela 5).

O acúmulo de forragem total e de lâmina foliar ocorridos durante todo o período experimental foi maior $(\mathrm{P}<0,10)$ nos pastos de capim-tanzânia manejados com $30 \mathrm{~cm}$ de altura pós-pastejo que naqueles com $50 \mathrm{~cm}$ (Tabela 5). Nessa condição de manejo, há maior intensidade de pastejo e eficiência de colheita da forragem (Difante et al., 2009), o que também tem efeito positivo na produtividade primária da pastagem. O maior número de ciclo de pastejo nos pastos submetidos ao manejo com $50 \mathrm{~cm}$ de resíduo (Figura 3) não foi suficiente para compensar o menor acúmulo de forragem por ciclo de pastejo e as elevadas taxas de acúmulo de matéria seca nos pastos sob altura pós-pastejo de $30 \mathrm{~cm}$ (Zanine, 2007).

O benefício do uso de maiores intensidades de pastejo sobre o acúmulo de forragem ocorreu em condição de pastos adubados (150 kg/ha de $\mathrm{N}$ ) e de solo com alta fertilidade natural. Contudo, em pastos não-adubados ou em solos de baixa fertilidade natural, menor intensidade de pastejo pode ser mais adequada para garantir a sustentabilidade da pastagem (Da Silva, 2004; Fonseca et al., 2008). Além disso, é importante sublinhar que a escolha do resíduo pós-pastejo pode ser mais flexível e deve estar em consonância com a eficiência de colheita da forragem e o nível de desempenho animal almejados no sistema de produção (Difante et al., 2009).

Por outro lado, os efeitos da condição pré-pastejo no acúmulo de forragem total foram distintos em cada nível de resíduo pós-pastejo estudado. Em pastos com $30 \mathrm{~cm}$ de resíduo, maior acúmulo ocorreu $(\mathrm{P}<0,10)$ quando foram submetidos à frequência de $95 \%$ de IL; mas, em pastos com $50 \mathrm{~cm}$ de resíduo, as frequências de $90 \%$ e 95\% de IL resultaram em semelhante acúmulo de forragem total.

A interação entre frequência e intensidade de pastejo para o acúmulo de forragem total (Tabela 5) caracterizou um mecanismo compensatório no pasto de capim-tanzânia. Provavelmente, para otimizar o acúmulo de forragem em pastos sob pastejo mais intenso (30 cm de resíduo), foi necessário menor frequência de desfolhação (95\% de IL). Neste caso, é possível que a menor área foliar e a baixa interceptação de luz pós-pastejo foram compensadas pela maior interceptação de luz pelo dossel na condição prépastejo. Por outro lado, pastos sob $50 \mathrm{~cm}$ de altura póspastejo precisaram de maior frequência de pastejo (90\% de IL) para expressar acúmulo de forragem total semelhante ao obtido nos pastos sob 95\% de IL (Tabela 5). Nessa circunstância, a menor interceptação de luz pré-pastejo (90\%) foi contrabalanceada pela maior interceptação luminosa pós-pastejo, que promoveu rebrotação mais rápida do pasto (Figura 2) e maior número de ciclo de pastejo.

Os níveis de interceptação de luz (90 ou 95\%) não influenciaram ( $\mathrm{P}>0,10$ ) o acúmulo de lâmina foliar (Tabela 5). Esse resultado evidencia que, quando necessário, o capimtanzânia pode ser pastejado com 90\% de IL, sem prejuízo à produção de folha, quando comparado à condição ideal de pré-pastejo (95\% de IL). Nesse sentido, quando o ambiente é muito favorável ao crescimento do pasto, condição em que é comum que, simultaneamente, um número maior de pastos alcance a condição ideal de pastejo (95\% de IL) relativamente ao número necessário, a flexibilidade para realizar o manejo adequado do pastejo pode ser obtida por meio de desfolhações mais frequentes (90\% de IL).

Em muitos casos, os efeitos das alturas pós-pastejo sobre o acúmulo de lâmina foliar e de forragem total foram dependentes da época do ano. Da mesma maneira, em algumas épocas do ano, os efeitos da frequência de pastejo foram distintos em cada nível de frequência de pastejo avaliado (Tabela 4). Essas respostas, além de caracterizar a complexidade dos efeitos das estratégias de manejo do pastejo sobre a produtividade do pasto, comprovam que o capim-tanzânia tem exigências de manejo específicas para cada época do ano. Realmente, estudos recentes com gramíneas forrageiras tropicais (Carnevalli et al., 2006; Lopes, 2007; Montagner, 2007) tem comprovado vantagens em manejar os pastos com altura pós-pastejo mais baixa no inverno para melhorar as condições para a rebrotação na primavera.

Tabela 5 - Acúmulo de forragem total e de lâmina foliar (kg/ha de MS) do capim-tanzânia sob alturas de pós-pastejo (APP) e condições pré-pastejo de 90 e 95\% de interceptação luminosa (IL) durante todo o período experimental

\begin{tabular}{|c|c|c|c|c|}
\hline \multirow[t]{2}{*}{ APP (cm) } & \multicolumn{2}{|c|}{ Forragem total } & \multicolumn{2}{|c|}{ Lâmina foliar } \\
\hline & $90 \%$ de IL & $95 \%$ de IL & $90 \%$ de IL & 95\% de IL \\
\hline 30 & $15740 \mathrm{aB}(282)$ & 17270aA(382) & 13090aA(289) & 13430aA(388) \\
\hline 50 & 13630bA(213) & $13740 \mathrm{bA}(256)$ & 11830bA(322) & $12260 \mathrm{bA}(328)$ \\
\hline Média & 14680B(183) & $15500 \mathrm{~A}(192)$ & $12470 \mathrm{~A}(173)$ & $12850 \mathrm{~A}(153)$ \\
\hline
\end{tabular}

Valores entre parênteses referem-se ao erro-padrão da média.

Médias seguidas de mesma letra minúscula na coluna não diferem entre si $(\mathrm{P}>0,10)$ para as alturas pós-pastejo.

Médias seguidas de mesma letra maiúscula na linha não diferem entre si ( $\mathrm{P}>0,10)$, para as interceptações luminosas, para cada componente. 
Da mesma forma que houve variação no acúmulo de lâmina foliar nas épocas do ano (Tabela 4), também ocorreram modificações $(\mathrm{P}<0,10)$ na composição morfológica da forragem produzida durante estas épocas (Tabela 6). No final da primavera, houve maior $(\mathrm{P}<0,10)$ participação relativa de lâmina foliar, bem como menores $(\mathrm{P}<0,10)$ percentuais de colmo e de material morto na forragem produzida. Do final da primavera para o verão, o percentual de lâmina foliar reduziu $(\mathrm{P}<0,10)$, porém ainda continuou em patamares altos, enquanto o percentual de colmo aumentou $(\mathrm{P}<0,10)$ e o de material morto permaneceu reduzido. Por outro lado, no outono, a forragem produzida caracterizou-se por menor $(\mathrm{P}<0,10)$ porcentagem de lâmina foliar e maior $(\mathrm{P}<0,10)$ participação relativa de colmo. Por sua vez, no inverno e início da primavera, houve $(\mathrm{P}<0,10)$ alta participação de material morto na forragem produzida, que também possuiu um dos menores valores percentuais de lâmina foliar e porcentagens intermediárias de colmo em relação às demais épocas.

As combinações de intensidades e frequências de pastejo resultaram em pouca diferenciação morfológica do pasto e, por conseguinte, reduzida variabilidade na composição morfológica da forragem produzida em uma mesma época do ano. Durante o inverno e início da primavera, o final da primavera e o verão, as estratégias de manejo do pastejo não influenciaram $(\mathrm{P}>0,10)$ a participação relativa dos componentes morfológicas na forragem produzida. Novamente, isso indica que, quando necessário, o pasto de capim-tanzânia pode ser colhido com 90\% de IL sem que ocorram modificações significativas na percentagem dos componentes morfológicos do pasto.

Apenas no outono, o único efeito verificado consistiu $(\mathrm{P}<0,10)$ no maior percentual de material morto na forragem produzida em pastos manejados com $50 \mathrm{~cm}$ de altura póspastejo em comparação àqueles sob $30 \mathrm{~cm}$ de resíduo (Tabela 6). Com isso, em épocas de condições ambientais menos favoráveis ao crescimento do pasto, como no outono, a utilização de resíduo mais baixo $(30 \mathrm{~cm})$ resulta menor senescência e perda de tecidos vegetais.

Mesmo com o estrito controle das condições do pasto em pré e pós-pastejo, a composição morfológica da forragem produzida variou entre as épocas do ano (Tabela 6). Esse fato evidencia o marcante e inerente efeito do clima sobre a estrutura do capim-tanzânia e sugere que, futuramente, pesquisas devem ser conduzidas para estabelecer ajustes finos no manejo do pastejo, que seriam específicos para cada época do ano.

Adicionalmente, destaca-se que houve pouca participação de colmo na forragem produzida, comprovando que as frequências e intensidades de desfolhações avaliadas permitiram bom controle desse componente morfológico nos pastos.

Tabela 6 - Composição morfológica da forragem produzida em pastos de capim-tanzânia durante as épocas do ano

\begin{tabular}{lccc}
\hline Época & & Componentes da forragem (\%) & Material morto \\
\cline { 2 - 4 } & Lâmina foliar & Colmo & $0,13 \mathrm{c}(0,05)$ \\
Final da primavera & $97,97 \mathrm{a}(0,45)$ & $1,90 \mathrm{c}(0,44)$ & $0,12 \mathrm{c}(0,04)$ \\
Verão & $86,67 \mathrm{~b}(1,24)$ & $13,21 \mathrm{~b}(1,23)$ & $3,65 \mathrm{~b}(0,46)$ \\
Outono & $70,85 \mathrm{~d}(1,24)$ & $25,50 \mathrm{a}(1,36)$ & $5,64 \mathrm{a}(0,68)$ \\
Inverno/início da primavera & $80,51 \mathrm{c}(1,24)$ & $13,85 \mathrm{~b}(1,40)$ & \\
\hline
\end{tabular}

Médias seguidas de mesma letra, na coluna, não diferem $(\mathrm{P}>0,10)$ entre si.

Valores entre parênteses referem-se ao erro-padrão da média.

\section{Conclusões}

A altura do pasto de capim-tanzânia tem correspondência com a interceptação luminosa do dossel na condição de pré-pastejo. As frequências de pastejo correspondentes aos 90 e 95\% de interceptação de luz pelo dossel e as alturas pós-pastejo de 30 e $50 \mathrm{~cm}$ permitem o controle do alongamento do colmo do capim-tanzânia. Para obtenção de maior acúmulo de forragem, o pastejo rotativo do capim-tanzânia deve ser iniciado com 95\% de interceptação de luz pelo dossel, ou seja, com plantas de aproximadamente $75 \mathrm{~cm}$ de altura, e rebaixado até a altura de $30 \mathrm{~cm}$ de altura pós-pastejo. Em situações específicas, o capim-tanzânia pode ser manejado com $90 \%$ de interceptação de luz pelo dossel ou com aproximadamente $65 \mathrm{~cm}$ de altura na condição de pré-pastejo para gerar flexibilidade no manejo do pastejo. A existência de interações entre as estratégias de manejo do pastejo e as épocas do ano indica a necessidade de estabelecer estratégias de desfolhação sazonais para o capim-tanzânia.

\section{Referências}

BARBOSA, R.A.; NASCIMENTO JÚNIOR, D.; EUCLIDES, V.P.B. et al. Capim-tanzânia submetido a combinações entre intensidade e freqüência de pastejo. Pesquisa Agropecuária Brasileira, v.42, n.3, p.329-340, 2007. 
BUENO, A.A.O. Características estruturais do dossel forrageiro, valor nutritivo e produção de forragem em pastos de capim-Mombaça submetidos a regimes de desfolhação intermitente. 2003. 89f. Dissertação (Mestrado em Agronomia - Ciência Animal e Pastagens) - Escola Superior Luiz de Queiroz, Piracicaba.

CARNEVALLI, R.A.; SILVA, S.C.; OLIVEIRA, A.A. et al. Herbage production and grazing losses in Panicum maximum cv. Mombaça pastures under four grazing managements. Tropical Grasslands, v.40, n.3, p.165-176, 2006.

DA SILVA, S.C. Fundamentos para o manejo do pastejo de plantas forrageiras dos gêneros Brachiaria e Panicum. In: SIMPÓSIO SOBRE MANEJO ESTRATÉGICO DA PASTAGEM, 2., 2004, Viçosa, MG. Anais... Viçosa, MG: UFV; DZO, 2004. p.347.

DIFANTE, G.S.; EUCLIDES, V.P.B.; NASCIMENTO JÚNIOR, D. et al. Ingestive behaviour, herbage intake and grazing efficiency of beef cattle steers on Tanzania guineagrass subjected to rotational stocking managements. Revista Brasileira de Zootecnia, v.38, n.6, p.1001-1008, 2009.

EMPRESA BRASILEIRA DE PESQUISA AGROPECUÁRIA EMBRAPA. Sistema brasileiro de classificação de solos. Brasília: EMBRAPA, 1999. 412p. (Produção de Informação).

GIACOMINI, A.A.; SILVA, S.C.; SARMENTO, D.O.L. et al. Growth of marandu palisadegrass subjected to strategies of intermittent stocking. Scientia Agricola, v.66, n.6, p.733-741, 2009.

LOPES, B.A. Características morfofisiológicas e acúmulo de forragem em capim-mombaça submetido a regimes de desfolhação. 178f. 2006. Tese (Doutorado em Zootecnia) - Universidade Federal de Viçosa, Viçosa, MG.

MATTHEW, C.; YANG, J.Z.; POTTER, J.F. Determination of tiller and root appearance in perennial ryegrass (Lolium perenne) swards by observation of the tiller axis, and potential application to mechanistic modeling. New Zealand Grassland Association, v.50, p.1-10, 1999.

McKENZIE, P.D.; MARTIN, F.G.; MISLEVY, P. Environmental effects on plant growth and development. In: WHITE, J.; HODGSON, J. (Eds.) New Zealand pasture and crop science. Oxford: Oxford University Press, 1999. p.29-44.

MELLO, A.C.L.; PEDREIRA, C.G.S. Respostas morfológicas do capim-Tanzânia (Panicum maximum Jacq. cv. Tanzânia-1) irrigado à intensidade de desfolha sob lotação rotacionada. Revista Brasileira de Zootecnia, n.2, v.33, p.282-289, 2004. MONTAGNER, D.B. Morfogênese e acúmulo de forragem em capim-mombaça submetido a intensidades de pastejo rotativo. 2007. 60f. Tese (Doutorado em Zootecnia) Universidade Federal de Viçosa, Viçosa, MG.

MOORE, J.E.; SOLLEMBERGER, L.E.; MORANTES, G.A. et al. Canop structure of Aeschynomene americana - Hemarthria altissima pastures and ingestivo behavior of cattle. In: HORN, F.P.; HODGSON, J.; MOTT, J.J. et al. (Eds.). Grazing-lands researcha of the plant-animal interface. Arkansas: Winrock International, Morrilton, 1987. p.93-114.

PEDREIRA, B.C.; PEDREIRA; C.G.S.; DA SILVA, S.C. Estrutura do dossel e acúmulo de forragem de Brachiaria brizantha cultivar Xaraés em resposta a estratégias de pastejo. Pesquisa Agropecuária Brasileira, v.42, n.2, p.281-287, 2007.

PEDREIRA, C.G.S.; ROSSETO, F.A. A.; SILVA, S.C. et al. Forage yield and grazing efficiency on rotationally stocked pastures of 'Tanzania-1' guineagrass and 'Guaçu' elephantgrass. Scientia Agricola, v.62, p.433-439, 2005.

SBRISSIA, A.F.; DA SILVA, S.C. Compensação tamanho/ densidade populacional de perfilhos em pastos de capimmarandu. Revista Brasileira de Zootecnia, v.37, n.1, p.35-47, 2008.

SBRISSIA, A.F.; DA SILVA, S.V.; NASCIMENTO JÚNIOR, D. et al. Crescimento da planta forrageira: aspectos relativos ao consumo e valor nutritivo da forragem. In: SIMPÓSIO SOBRE MANEJO DA PASTAGEM, 25., 2009, Piracicaba. Anais... Piracicaba: FEALQ, 2009. p.37-59.

SBRISSIA, A.F.; DA SILVA, S.C.; SARMENTO, D.O.L. et al. Tillering dynamics in palisadegrass swards continuously stocked by cattle. Plant Ecology, v.206, n.2, p.349-359, 2010.

STATISTICAL ANALYSES SYSTEM - SAS. SAS/STAT: user's guide statistics, Versão 6, 4.ed. Cary, USA: v.2, 1993. (CD-ROM).

ZANINE, A.M. Características morfogênicas, estruturais e acúmulo de forragem do capim Panicum maximum cv. Tanzânia submetido a intensidades e freqüências de pastejo. 2007. 134f. Tese (Doutorado em Zootecnia) Universidade Federal de Viçosa, Viçosa, MG. 